\title{
Analysis of Intellectual and Emotional Struggle Dramatic Techniques, in the Poetry of Khalil Havi and Mahdi Akhavan Sales
}

\author{
Shahla Shakibaeefar \\ Department of Arabic Language and Literature, Payame Noor University, I.R of Iran
}

\author{
Doi:10.5901/mjss.2016.v7n2s1p494
}

\begin{abstract}
Struggle techniques, from the most basic theater techniques that challenge the current unfavorable situation, the situation is ideal to showcase. This technique, with the creation of the contradiction between the phenomena of the universe, because the life is tangible visualization, and lyrical attitude with the bond issue, its relation with time, society and reality allows. Khalil Havi and Akhavan Sales, modernist poets of the same generation are, in social situations, similar political life, and from philosophy of existence have been influenced. In the occult lyrics, from the symbolic language and different ways of performing, in particular struggle to the social component picture of our time, have benefited. Check out Havi and Akhavan Sales lyrics, indicates that intellectual struggle, in poetry Havi with doubt and certainty struggle, controversy modernity and traditionalism, also in contrast Being and Nothingness Connected, and Akhavan poetry also by doubt and certainty contradiction About heavenly things knowledge, deal with the traditions and historical determinism, as well as life and death struggle is linked. Emotional conflict, In both the poet's poems with desperation and hope, as well as with purity and filth in the Havi poems andself-esteem and inferiority in the Akhavan Sales lyrics linked.
\end{abstract}

Keywords: comparative literature, drama, struggle, Khalil Havi, Mehdi Akhavan Sales.

\section{Introduction}

Dramatic expression, one of a variety of literary interpretations considered. In the contemporary period, other forms of art, including poetry, stories and music, up to the objectivity of their content, presentation techniques are applied (Algham, 2006, 39). This technology has various techniques such as struggle, dialogue, polyphony, suspension, and is the projection node (Algheisari, 2006: 45), struggle technique, the most important factor for the attractiveness of a plays are, and it provides the natural history, and in terms of personality struggle or opposition force, the events show disembodies, applies (Baraheni, 1983, 161).

Research on the technique of struggle, since it is important that this technique with a focus on social struggles, and the creation of the contradiction between positive and negative events, thoughts lead to tangible incarnation (Esmail, $1988,305)$, as well as creating changes and new visual language, and the texture of poetry, and literary work of lyrical approach frees absolute bondage; its relationship with history, mythology but also the entire world, and phenomena consistent or inconsistent enables it (Algheisari, 2006, 35-38)

\subsection{Problem statement}

Struggle dramatic techniques, one of the literary arts in contemporary criticism that the next bilateral artwork gives and accident, or think positively affect the event, feeling or thinking puts negative (Esmail, 1988, 279-280) also describes the meaning and convey the truth is important. There are similarities between Havi Khalil Mehdi Akhavan Sales, including socio-economic living conditions of the same, unaffected by the idea of humanity, the use of symbolic expression and dramatic ways, all led to, comparative research between the two poets, in how to apply the techniques of struggle, it is necessary to describe the intellectual and emotional implications.

This study has tried, for comparative presentation technique intellectual and emotional struggle, in the poetry of Khali Havi and Akhavan Sales review, and to answer the following two questions:

1. Why these two poets, in the image of intellectual and emotional content, conflict dramatic technique, have to work?

2. In the context of the application of this technique, what similarities and differences in the lyrics of these poet, is there? 


\section{Background}

Some of the most important articles about Khalil Havi written as follows:

"Studied existentialism, in the poetry of Khalil Havi" (2011) from Hosein Nazeri and Kolsum Sedighi, the two journal of philosophical knowledge, the ideas are rooted in the poems of Khalil Havi is considered. "Analysis of the psychological concepts of fullness and love, in the poetry of Khalil Havi" (2011), by the Hosein Nazeri and Kolsum Sedighi, in the Journal of Arabic language and literature, the psychological origin of the concept of fullness and love, in the poems of the poet analyzes, and "the personality of Christ, in the poetry of Khalil Havi" (2013), from Hadi Rezvan and Nasrin Moloodi, the language magazine suggests that the myth of Tammuz and the religious symbol of Christ, the Havi poem's.

About Akhavan Sales, the most important articles are:

"Akhavan in tent Khayyam" (2005), from seyed Mahdi Zarghani, in the Journal of Literature and Human Sciences, Mashhad, which influences Akhavan of Khayyam's poetry, has been examined, "Check archetypes, Akhavan Sales poetry " (2011) , from Masood Foroozani and Zohreh Soorani, a specialized journal peak light Persian language and literature, which some consider Jung archetypes like a shadow, self, mask, etc., in the poems of the poet's analysis, narrative techniques, narrative Mehdi Akhavan Sales poems "(2012), from Mohammad Shadravimanesh and Azam Baramaki, the magazine of Persian literature, to analyze some techniques of narrative, poetry has Akhavan, some articles on the struggle element, written in Arabic literature include:

"Personality Psychology Review, the Mutanabbi lyrics " (2013), by Yahya Maroof and Moslem Khazali in Arabic literature magazine that, in analyzing the struggle, in three levels of urban wetland accommodate character has pointed out, and " The conflict between life and death, in the poem of Abu atahi and Naser Khosrov ", (2014), from Abbas Yadollahi in the light language magazine that, in contrast Being and Nothingness, in the poet's poetry.

In Persian literature articles that have to deal with this element are:

"Element of the struggle, the story of Siavash" (2008) by Kazem Moosavi and Fakhri Zarei, in the Journal of Literary Criticism ", the element of struggle in Khosrow and Shirin" (2013), Mohammad Amir Mashhadi and Eshaq Balochzayi, in Sistan and Baluchestan University lyrical literary magazine, and "the study of struggle, the story of Rostam and Sohrab", (2013), from Kazem Moosavi, and Fakhri Zarei and Gholam Hosein Madadyar, helpful, courteous and language in the Journal of the Faculty of Letters and Human Sciences Kerman, all the reviews of this element, its variants have been analyzed. Considering that, since the dramatic struggle comparative analysis techniques in the lyrics of Khalil Havi and Mehdi Akhavan Sales research has been done, the authors feel it is necessary to have efforts to examine this element, and how to use it in the poems two poets, to determine the similarity and difference, and the new look of their world, in their view.

\section{The Position of Struggle Techniques in Showmanship}

Struggle means struggle, struggle, drag and drop applied (moin, 2007, 894), the most prominent elements of the format, and it is a beauty. This technique, sometimes as a result of dealing with thoughts and emotions hero, and sometimes in struggle with other people experience. Can be started struggle an imbalance gradually becomes critical, oppositional and finally reached the tipping point. (Hamadeh, 1985, 162)

In general it can be struggle, divided into four types: physical struggle between two challenging character (protagonist), the crisis touches the display, and iPod challenger (antagonist) that contemplates the protection of existing conditions (Macci , 1992, 82), mental tension, emotional tension and social struggle (Mirsadeghi, 2008, 320-321). The movement of struggle in three leap (struggle without reasonable grounds, between the two opposing forces are formed), static (slow movement of the contest, and the reader does not cause), and progressive (contrast that with reasonable grounds, and gradually the peak goes) can be studied (Hamadeh, 1985, 162).

\section{The Position of Struggle Dramatic Technique, in Arabic and Persian Literature}

The issue of contradiction in the lyrics, has two aspects: the time is literal, and related to the aesthetics of poetry, and sometimes does, with philosophical and social themes linked.

Contradiction in terms Traditionally, there Arabic and Persian poetry, and in view of its limited application in the context of small gestures, and no way to access the content and structure in general, are removable and replaceable (Soleiman, 2006, 175), not It can be called struggle dramatic.

Semantic paradox in contemporary literature, is a great place, and often not visible in the construction literary work, 
but also in deep layers of a literary work lies. This type of interpretation is sublime in art (Shafi'i Kadkani, 1989, 37), and was associated with the structure and poetic images, we can refer to it as of the Such as display.

\section{The Themes of the Poetry of Khalil Havi, and the Status of the Struggle Technique in Its}

Havi should, the poet-philosopher, he said. Poetry illustrator crisis inherent in the discovery of knowledge and full of deep meaning intellectual, and emotional struggles (Shafie Kadkani, 2001, 148). struggle of Ruined city Utopia and despair in the realization of the Arab uprising, the most prominent themes of poetic doubt and faith, is (Esmail, 1988, 341-342). Experimental design such as river ash, shrub harvest hunger, hell comedy that three of his poems, clearly revealing the composer's mental struggles occur because the password river dynamics and stability symbol ash, marsh harvest of plenty, hunger, poverty implies, the symbol of the torment of Hell, and comedy is a symbol of joy.

\section{Mahdi Akhavan Sales Themes and the Status of the Struggle Technique in Its}

Akhavan Sales, contemporary poets, has always tried to, his language to distinguish from normal. The use of narrative and dramatic techniques, such as struggle, dialogue, suspense, etc, as well as the discovery of the contradiction between the phenomena of the universe, and militancy is rooted in his radical Khayyam (Shafii Kadkani and Kakhi, 1991, 273), basic the themes he is.

Court of "winter", "end of the Shahnama", "from this Avesta" and, "The small fall in the prison yard", full of themes of protest and struggle, with social reality. It can be said, social contradiction in the Court "and the epic", and "Avesta" has reached its peak, sometimes ambiguous language has taken on, in addition to the political struggle, the struggle of intellectual innovations. However, the contrast in the two offices "Winter", and "Autumn in the prison courtyard", the depth is less. (Zarghani, 2005, 35-40)

\section{The Intellectual Struggle}

Intellectual struggle, then there is that two contradictory ideas with each fight. (Mir Sadeghi, 2001: 73), this type of struggle in the deepest layer of contradiction comes, most of the anti-poet tells you. ( Zarghani, 2005: 26)

7.1 intellectual struggle, in the poetry of Khalil Havi: Havi Lyrics, full of deep human ideas, and philosophical. The specific circumstances of the poet's life, a never-ending suffering, a crisis of understanding the nature and captivity in chains traditions, including the factors that led to the emergence of mental struggle was in her poetry. Havi Lyrics intellectual struggle, doubt and certainty with struggle, controversy traditionalism and modernism, as opposed to thinking about death and fear of death, is associated.

7-1-1- against doubt and certainty: the confrontation of doubt and certainty, including intellectual struggle, in the poetry of Khalil is Havi. This concept perspicacious poetry "train station", in connection, where the singer is not among compatriots, and resurrection of their existence, doubt and certainty stepping on lines (Havi, 1972, 197). In Ode "Sodom" on the false certainty of insensitivity, the realization of political upheaval on Against, and trained doubt seen, permits will not see an illusion (Havi, 1972, 77). "The Sailor and the Dervish", with the creation of two contradictory character Sailor and Dervish linked. The "Dervish" poem, a symbol of certainty and stability in Sufi values, and achievements old. He did so with his philosophical thoughts were only that, would not accept any change to the thoughts and life here:

The old friary / two feet of mud taken root, and remained motionless, everything that casts dead, sucks, / in the skin between the parasitic plant / algae elderly, and Ivy rough you go, / ... in my house of God, and the distance of time, settled (Havi, 1993, 41-42).

In these lines, algae, has been a symbol of evidence, including documents (Horn on age) it reflects the old Arab culture. The ivy, which is equivalent to the traditions of the East, rooted in existence, and they are open to change.

While, seafarers personality adventurer who, trained in cultural values doubts. In order to discover the identity of her, are nowhere to journey, and this journey is familiar with two contradictory experience, the first East Coast, and indolence in the clergy crawl, and it refers to as' Clay death ", however, and another Western civilization, immersed in the material, and it "Protected clay " is called. Sailor after examining all the tools, lost his certainty, and desperately Jewish story ends:

After suffering seasickness was caught, / the infinite of the universe, at the mouth of the caves step, / ... given to me in my eyes, / lighting roads turned to silence, / me to leave, to the extent that I do not know, step IX / remote ports, never not Deceived me, / some thorny flower, / and some dead flowers, / Oh what a thorny flower that, in the I fuel, / what is the flower of the dead, John gave ( Havi, 1972, 19). 
7.1.2- modernity and traditionalism struggle: anti-traditionalism and modernity, of other types of intellectual struggle, in the poetry of Khalil Havi is. According to the poets, ancient beliefs about the infertility, and fire downturn in the face of life's burning. This type of struggle, different levels due "straw blowing", appears. As an ode itself is clear evidence on this point, because the straw with their calming sounds of the sad and secret evidence in the ancient cultural traditions, and to live free from excitement, while wind roared visitors, a symbol of resurrection and modernity. The first paragraph of the poem, poet, mental tension, the valve of terms such as "monastery, items, Inkwell, old sheet, dubbed seats, Mummy", an ancient symbol of commitment to science, and culture are Arab history, as well as the words " Door, Echo prissy, they are crossing, slaying, cursed me ", which expresses the poet's sentiments, to be renewed, is clear.

Church / between me and valves, pen and inkwell, / echo weepy / mass old paper, / will have been crossed, / one or two steps toward the gate certainty, / then the way, I ... drops You drip blood, makes me hurt, and cries, / How long am betrayed, and brow and my lungs such as saliva, / to the titles and pour chair (Havi, 1972,167).

Another part of the poem, as opposed to traditionalism and modernity, the window against the pious man "Nasek", and the poet is visible. Pious man, a symbol of devotion to tradition, and his efforts to remove the rotten chain of imitation, and the renewal of the madness and follow the devil, its interpretation. While singing and step, the girl brown desert, the sand is immersed innovation:

Pious man inhibitor in serum, / I have revealed, shocked, asks, / Do your duty dereliction of highly trained, / Do you have a madness, happiness and gone to sleep at midday, / Is Satan deceived you. is?, / I Bedouin girl brown, / I was with the words, / in sand, / I was immersed in darkness and fire (Havi, 1972, 185).

Article VIII of the poem, intellectual struggle And modernization traditionalism, based on the wind against the old stone walls can be seen:

Wind is so hungry, steel breaks, / the old walls that have been turned to stone, eliminates, / the brown soil's integrity, it gives, / as at the beginning of creation, he gave, / soil, eager to embrace the sun, night lightning, he / she (soil) to bring the pain, and (Wind) luster he (lightning) to reveal (Havi, 1972, 180).

Documents the word "hunger", the element " Wind " and using the word " Files ", in addition to the tremendous power of renewal, and dynamics in struggle with cultural traditions that, Image "Installing antique" is the implications it refers. Havi enjoying sentences (Returns to what was babysit him and crave the sun), the success of innovation, speaks on ancient beliefs. In this poem, sun freedom mystery of ancient cultural heritage, and night lightning " Thunder guide ", the symbol of the suffering is huge, Arabic nation should have a transformation and resurrection, to take a shower.

7-1-3- thinking death and fear death struggle: since the human eye, to soil Place are opened, longing for immortality and the fear of nothingness, sprouted in him. Havi in his poetry, sometimes love to live and sometimes die of longing to speak, because her childhood and adulthood critical loads forfeiture, great taste and taste alone. This kind of contradiction in due "bloody ground", can be seen. You could say this poem, the shadow of the poet's unconscious, because his two brothers and his little sister, because the risk of a fatal illness, lost (Havi, 1984, 68).

The turmoil of ground red / smoke tobacco, wine and the tab base-born, / and fear that when the goddess Anahita wishes, my hands are tied, / I robe but no shadow and light, almost, / But the light eyes -looking There is / (Havi, 1993, 61)

The term " Mill " the key to a life that is, in the whole universe, human and time to their destruction. The term " Red ", due to his association with the word Mill contains a negative connotation, expressing willingness to nothingness. But the combination of "Smile in my eyes ", meaning inconsistent with the "bloody ground" there, the dream of lasting life, story, because the eye symbol female, is, and will draw enjoyment of, and desire for life. The "Anahita", goddess of love, life and fertile, the poet always fears that the hand of the hands of the goddess, to be released (Nazeri- Sedighi, 2011, 135) and lamp life here in the taps over. It can be said, the interaction of these two different thought, rooted in the philosophy of being pursued by the composer.

This concept due " Lazarus " is also linked. In this poem, wife Azar, password vitality and fertility, and in his heart, the desire for procreation and fertility Rears, and the other symbols Azar, cold and destructive force:

Woman regrets that, in the context of keen, / ... such boat that thirsty, warm afternoon on the beach to move quickly, / in the arms of a man, do not give him refuge, / ... along with fever, fatigue, / cold has been a dramatic way, he / she is dead, inside my house, he / she would have found the fallen dragon (Havi, 1972, 346-347).

At the end of the poem, wife Azar that, in the first lines of code fertility, has become contradictory personality, to not indicate that infertility, and in the hope that the death of all his work, from being wiped out:

I still waves the white facade fades, I ... signs of the shadows, and reject the work of my legs disappear, I reproductive effects on cluster hyacinths, which have grown locust teeth, fading facades, / works growing fruits, from Light brown sun that has the taste of ashes, faded facades / (Havi, 1972, 334-335)

In another part of the poem, the poet's grave, now wants to bury her in a hole, hot, and hot and soft soil might 
come to him. Because the warm soil makes the sprout's body, and again come back to life. On the other hand, in the poem with the question "Who am I that prevents wheel flares fire, among my people", speaks of the realization of the dream of an end to death. In fact, he wants to live among humans flow:

Strangles deeply dug, / a badger, / it's the end of the dig, / oh over my body Not landing, / new living reddish soil / earth roots, look within, and in the wrap, / my body embalmed to cover the territory traveler, / decided Lime Like sulfur rock / soul sad cry, / people who chews his fire wheel, / I am the fire from them Eliminate / (Havi, 1993, 341-345)

7.2-intellectual struggle and how it works, in Akhavan poetry:

Of course, every great artist is a paradox at the center of his existence ... creativity, but sometimes this is not a contradiction to emerge. Akhavan Sales even so, his lyrics are defiant nature, and full of struggling thoughts. (Shafie Kadkani, 1991, 272-273). Meet the humanist philosophy of the West, particularly the influence of the ideas of Khayyam, the field of intellectual struggle, has provided in his poems. Various issues such as opposition to doubt and certainty, to identify the objectives of the creation, existence and struggle against the force of life and death, the most fundamental aspects of the anti-intellectual Akhavan, form.

7.2.1-cognitive struggles: including Available intellectual struggles in Akhavan lyrics, cognitive struggle can be cited. In perspicacious poetry "ignorance", his intellectual struggle, the fundamental concept of divine truth, is associated. In this poem, the poet of historical religious character window, Mazdak first of his ignorance about what just across the universe speaks, then the use of a symbol of Zoroastrianism, the discovery of the mysteries of creation, and knowledge of Ahura Mazda and Ahriman story (Akhavan, 1981, 80). This type of struggle, in "a house in the distance," well, it's seen far in the distance Akhavan of existence, is the eternal home, but the road to eternal home, and his luggage vague. (Akhavan, 1981, 7). The wall display of "Shahnameh end poem," the first poet of mental contradictions based on the nature of the element of time, then the failure to detect this element is based. It seems Akhavan, with all connections and knowledge that characteristics of the present century, a century it away, unmarked and unknown knows, and how it is not conquest on:

Where is Han, / capital, the tilt regulations crazy century, / the night bright as day / days with his tight, because the bottom of the legendary endure night, / with castles hard to hard and steadfast, / With a smile meanly sneak around his gate, cold and alien , / ... century smiley faces, / Beyond the orbit of the moon, / ... the capital of such a century, / who? , I In which unmarked peak, / in what way? (Hoghooghi, 2014, 115)

This section of the poem, the epic phrase (Han's), which expresses his anger to hatred, or revenge of the present century, begins. The lines (the capital of this small century, on top of what is unmarked, / in what way), from ignorance and lack of understanding Akhavan, to indicate the current era. On the other hand the successive and contradictory traits, such as tilting ceremony mad century, pastors such bright days, days with his tight and that, for the coming century, indeed, show the depth of knowledge and understanding of the poet, is the time. (Noori, Konjoori, 2011, 136-137)

7.2.2-Against hereditary determinism: The intellectual struggle Akhavan Lyrics, can be cited against the inherent inertia. In due "watching" him, the convoy Murray to confront that, the cracked wall on the move, and the idea of the traditional black garment, and force the sleepy ancestors, their clothing is made. (Akhavan Sales, 1379, 56), this concept also Due "inscription" is visible, where the poet is drawing a crowd that, on the one hand boulder Aegean algebra beliefs, pressed on his arms and on the other hand, the Following are struggling with this slate. Composer relying on line (hay One two three), audiovisual show of community struggle, the ideas of inheritance creates static. Although the hardship and struggle, but in the depths of the kind of hope and enthusiasm, to discover the secrets of his existence.

Fall came and went, as far as rock was there, / one of us who was more free Her chains, went up; then read: I ((someone knows my secret, / that it's going to handle it,)) / ... and the full moon night of the Shatt al-Jalili, / hay, one ... two ... three ... again, / hay, one, two, three, again, / sweating, mourning, Curse- " Sometimes we cry. "/ What was heavy, it was sweet, but hard to win. (Hoghooghi, 2014, 152-153)

This intellectual struggle with perspicacious "legacy" poetry is also linked. In this verse the word 'coat, a symbol of culture, and its dialogue with legacy words, old and dusty days, the roots of this culture signify its heritage. Since the legacy, that is the financial, contract and contract to survivors without it, can not be said of the contract, hands in coat, carrying a sign that it is mandatory. Also when the poet, are scrambling to replace the garments themselves, the truth of determinism against the traditions of painting that has shaped his life and fathers in this way, he says. On the other hand at the end of the poem, Akhavan your Overcoat ancestors are believed to be part of, and demands that the next generation, preserve it. The deep satisfaction poet in keeping the fur coat, a wave of protest and discontent says:

old Fur coat I / tattered old relic from times that were dusty, I ... years from the earlier, on the shores of the Oxus productive, / so he tried wholeheartedly, / so do the fur coat, the new foundation ,. I ... years of this before me, / I stalked her fur coat, my new foundation. / with thousands of other filthy sleeve, the liver took the cry: / ... of, my child! / Hear and alerts, / And I like the aged forever, I and shower on you to work with. / Lake No you Let this grief. / Ku, brocade coat 
color, you know what you, / center scrapbook old fur coat is my cleaner? (Hoghooghi, 2014, 120-124)

7.2.3- Existence and nothing Struggle: other types of intellectual struggle in the Akhavan lyrics being and Nothingness conflict can be noted. The roots of this type of struggle must be sought in the ideological ideas poet's. Chaotic political, social, especially the translation of works by authors such as Nietzsche, Sartre was due to Akhavan, in some of his poems on the one hand, the rejection of metaphysics' world and beyond, and on the other hand due to the inclination, and to live the Muslim community and believe in God, have faith in religious values. (Vaezzadeh and Qavam, 2010: 26-31), this kind of struggle with the "Prayer" poem, in the relationship. As the poet of his own existence with nonexistence of God, a contradiction is created (Hoghooghi 2014: 201)), this type of struggle, as well as in the "hunting system" poem can be seen. The Akhavan seles poem, cold silence between passion and evil, life and death, as opposed to its creation. He believes in destiny game hunting, and the hunter when intoxicated with wine of life, the sudden death are captured. In the "The message of the end" poem, as Sartre to deny God, heaven and hell are discussed, and also the question of the meaning of life at the time, and on the other hand and not his death, at the same time speaks :

Each of us, in the Foggy legends, / when we thought, / God, but to deny, / if, / with the self does, and it is the sigh, / But heaven and hell, are we dead is. (Akhavan Sales, 1982, 97)

\section{Emotional Struggle}

Emotional struggle, tension filled most of the controversy, the play is, and thus the formation of spiritual, human nature is formed between the two forces (Rezai, 2003, 62). By analyzing this type of struggle, can be realized in view of a display character, and had its roots sometimes in person and sometimes emotional, social crises can search.

8-1- Emotional struggle poem by Khalil Havi:

Disease father suffered severe childhood (Alhor 1995, 62-67), romantic failure, failure of successive Arabic countries, and live in a community that was gradually stripped of spirituality (Hati, 1978: 575), in the form of negative beliefs, and spiritual contractions Havi Khalil has been very effective. So we can say that the emotional struggle, rooted in place of his poems, and most of hope and despair valve struggle, as well as purity and evil battle, is studied.

8-1-1- Against hope and despair: the most common emotional struggle, in the poetry of Khalil Havi, can be used in battle, hope and despair. This type of struggle on the part of the lyrics, the fruit of the social aspirations poet's. In this regard, the perspicacious "in May and Lightning" poetry, his light shine in the beginning of hope, an Arab victory, but before long, silent shadows and despair dominate light Therefore, the fail (Havi, 1972, 407 -408). Due 'eighth trip Sinbad ", the ongoing confrontation between hope and despair, the dream indicated the political resurrection, hope over despair finally been victorious, the dream child birth and migration seasons crocodiles experience. (Havi, 1972, 225). In due "Laazar", occurs when the emotional struggle, the poet's sense of hope and passion Azar wife, with despair and grief to return wife combines:

Paving house sings, / threshold in wine, carol is, / and the curtains are green grief, / the green wall, / plants grow on the door, / my lover came back from exile, death, I. Black was ..dark / off the boat, I ... why his tomb was opened as dead sad? (Havi, 1972, 320 324)

Poet based on the verb " Greening " that, here is a symbol of fertility and happiness after grief, as well as giving life to inanimate objects (such as stone, Topper) wants, feelings of vitality and hope to convey to all living creatures. On the other hand, documents Greening action to the word sorrow, of a contradiction and fusing grief, with joy, as well as the use of Phrase " Lacquer Black, boat dead and sulfur flames blackened " which, at rest and not have a password, from despair wife Azar tells.

Against despair and hope, sometimes linked to the contradictions inherent in the poet. This type of struggle, the perspicacious " When vision " poetry can be seen . Reader this poem before traveling to England, and in describing the fate His bitter, written in exile. His negative perceptions of their mental, wife of valve overlap between the states. As an intellectual struggle that the poet tries in the form of questions to Dave, his doubt and despair, and hope for the future to make sure that:

You see, in the marshes full of ingrained, / I see you, Dirty water mixed with mud, to fully awake, / you can see, the old crocodile then turned poisonous tree Labeling, / who flies with his skin, / leech and wolves to protect you, / Do not you hear an echo sound / silence caves, to encourage fanfare, / Is it within my veins full of wine Sun not seeking, / Do not you see that my blood flowing Dirty water, / the chandelier of green health-conscious person, and fertility make, / Is my face the nakedness of volcanoes, cannot you see?! / and fire, my shoes chew, and The hands-down cast / (Havi, 1972, 158163)

Whole words used in this verse, two different species creates space. Words such as (Mold, a poisonous tree, crocodile and old-fashioned fear flies and leeches and Wolves), negative space and thoughts are full of despair induced 
by other words such as (Hazeej, highball sun, chandeliers, wellness green, nozzle and Berkan etc.), positive and inspiring atmosphere depicts. Remove preposition, the line " Transmitting this mold ", and to use it in a sentence " Chandeliers of green wellness " implies rapid change, fear of the future, the passion of life.

8.1.2- Purity and filth Struggle: The emotional struggle, in contrast to the clean and dirty poem by Khalil Havi can be cited. It is aspiring poet, to portray the melancholic battle clean Ahriman and antiseptic Ahura, there Asleep vast, Makes fertile. This type of struggle in his poems, often associated with social emotions. In the "The City of deception and purity poem " the first simplicity of the human soul, then the influence of deceit and deception, in which he speaks. He depicts the city, the spiritual sun vanishes, and is slowly awakening sense His mourning. (Havi, 1972: 238). In Due "face of Sinbad", the essence of being the first pure, relying on secret Bedouin(Gypsy )depicting, showing God's Bedouin, is evident in his face, and the waterfall of fire and wine, the blood boils (Havi, 1993, 201-204), but gradually learned the name indicates, the mind and to forget the house of the deposit to be removed. It also, in another part of the poem can be seen, where the poet with monologue technique, the essence of human nature and civilized character of current capacity, a dichotomy has been created:

And along with him at the door "Soho", steps I, / and him alone in a vacuum, steps have his / her face more older than my face, / but his expression does fever, / and humiliation not days, / his face says, we both are one (Havi, 1972, 212)

He also Due "Laazar", section "Magdalene" the lust of the flesh of Mary Magdalene, the divinity of Christ provides contrast (Havi, 1972, 342-344) this type of struggle between the central character of the "Azar" poem, and "wife" also can be seen, where fear and panic Azar with claws His chaste wife's body, in search of his love, the pain. Relying Poet on the word "strange", contradict these two characters is clearly stated:

Her doorstep sees me like grass, / I've alien spouse / eager to build upset me, got on the Shine, his / her teeth, to scare them watered, / I sought her eyes sealed, / and in the eyes of her modest women / (Havi, 1972, 322-323)

8-2- Emotional struggle, in the Akhavan Sales poetry:

Emotional struggle, other types of struggle is Akhavan poetry. The paradox can be emotional, verbal paradox was highlighted in his works (Zarghani, 2005, 334), in both social and natural approach, can be investigated. Events such as the failed coup of August 28, and the overthrow of Mossadegh underlying the formation of emotional struggles, social struggles over natural provided. This kind of contradiction from two angles against despair and hope, humiliation and selfesteem will be discussed.

8-2-1- Against despair and hope: Akhavan his poetry, hope and despair puts a mirror. Jasmine is always dominant in his poems of hope. As far as we can say, is disappointed the flagship poets (Shafie Kadkani, 2001, 63). This struggle is often the result of living in a society made her night. In written "Kaveh or Alexander", this concept is clearly seen, since the sound of hope and victory Akhavan takes, but before long, his cries, political repression to silence in the cold like hell. (Law 2014,111) "Saboohi" Poetry clear himself Moving at night March and finds a naked tree, crying and desperate there, but fellow citizens whimsical On her horn fallen tree singing joy and hope to answer him. (Law, 2014, 195) in Due "end of the Shahnama", the poet's spirit of defiance victories, with Cry failure blends. He had the reputation of external experience, the poetry of despair and failure to compose, but the world inside the world of invincibility and battle (Zarghani, 2005, 433).

With fearsome encounters Our blade, sharp, / roaring hard Forces us hard, / jump granite beam splitter Haman, spicy /...ma/ conquerors boast castles, history, I ... We came to win, / A miserable vain conversation! , Other screens now, / s hands, the lives of the well will not be disappointed brother, / man, man, man, / Oh, no, / Winners humpback and old to stay, / Our blade rust-eaten old and tired, / we Forces eternal silence, / Our bar Break our wings, / the winners in the on Winder / (Hoghooghi, 2014,116-119)

The composition and terms used in the lines (with fearsome encounters .... our bar, spicy), poetry in space where His Excellency, strong and powerful music of his wave, puts it gives epic tone. In terms roar, jump silent vibrant "R", anger and rage is epic double. But in the next row, change your thoughts and change the emotional space of poetry, was to occur, and Kebria and roaring in distress failure. Whole words this part of the poem (Our blade rust-eaten, Forces us off, Log property, the wing is broken), the meaning of words in the direction opposite to the first part (Our blade sharp, roaring Forces ...), are, especially repeat the word man , and the creation of a line without artistic images, in the most succinct terms, the frequency of phonemes "e", expressed his helplessness, pulls back the curtain of endless suffering. (Noori, 2011, 129)

In parts of Due "snow" itself like a wolf lamb and free milk drunk knows, hopefully step in the transformation of his country affords, while in other parts of the poem itself stork sad, and permitted The old mill is old, that his political sacred ideals are shattered.

I go like a wolf, drunk milk free, free, / and gave way at every step, / g read more song, / the happy greeting sent, / 
This gave regal heavenly ..., / stork sad, with his her characters, / ... before the period of aging hardware alone, / Because my disability chains on my feet, / ... these old and obsolete mill broken butterfly, / no wheel bring vitality and clicked my beak wings. ( Akhavan Sales, 1982, 111-113)

8-2-2- Against humiliation and self-esteem: a confrontation little aspect of human existence, the supreme spiritual dimensions, other types of emotional struggle, Akhavan poetry is, and sometimes social emotions associated Akhavan is. This concept Due "Sangestan city", where the prince, his people into battle with a horde of pirates calls there. The poem Prince symbol of self-esteem, and the cause of the consciousness, and Pirates of the petty aspects of human nature, and all of the excitement of his undetected civilization implies the (Farzi, 2012, 120-121). "The dogs and wolves", outlining two ways of living, welfare and poverty, hunger, free of suffering secretary. In this poem, dog Password dependence and negative patterns of personality that, to continue the peace, any degradation to the lives of purchase, and a password wolf who, at the same need, the need for and against Cadaver world, head-to-no the world did not bend: Singing dogs, I ... Kitchen the Lord, since, / the soft sawdust sleep, / what is delightful and pleasant, and then, I ... days of eating table scraps, / and if it not the bone, / ... but whip, / The other thing is, /...right that painful right, / but the uterus is Lord, / have since subsided anger, / who on his head and put on shoes , / ... singing wolves, / ... not us warm corner of the den, / slot mountains, shelter, / ... the enemy is lurking, permanent, / ... outside, cold, inside, This fire-eating, / ... In this cold, hungry, wounded, I. But freedom and dignity, / Guardians are, freedom, free. (Akhavan Sales,1999, 29-32).

his means, among horizons mythological poem in eighth reader, can be seen. The poem Rostam password selfesteem, and composer based on ancient and lofty words like (round, Sajestani, mountain, etc.), it is up to the greatness and power of Iran's champion, will be considered. On the other hand, Shaghad password is evil and negative pattern, the poet seeks to describe the fear, and cowardice that character. Composer relying on the metaphor (wells as deep and wide, without His shame disbelief), the shameless betrayal, as compared with the depth of the well described. Sajestani valiant hero, I mountain humps, man place man, Rostam hands, / in the deep dark wells tags vast, / death everywhere on the floor, and the walls of his spear and Dirk / well treachery cowards, / well posts, wells without Acknowledgements , I well as a profound and his wide, without His shame disbelief, / and sad and surprising ... Suddenly, I on the lip of the hole I shadow Awe filled e-fading shadow, he saw, he / she Shaghad, the stepbrother was. (Hoghooghi, 2014, 280-283)

269-270) this type of struggle in the first paragraph "epic finale" is also there:

It breaks the grip of lawlessness, / ... sometimes as if dreaming, / her in court luminescent October / landscape merry way and saw Zarathustra, / ... in the meadow clean, and bright moonlight sees, on / off false / caravan blaze died in swamps, / ... Remember the days of glory and pride infallibility, / writes happy / sad tale of exile. (Hoghooghi, 2014, 114115)

\section{Conclusion}

Research on Khalil Havi and Mehdi Akhavan Sales Lyrics, suggests that, in the context of intellectual and emotional struggle, of the most dramatic fashion mojo, have been in his compositions. Intellectual struggle in both his lyrics, the application is very wide. Havi poetry, as a result of the influence of votes Poets like Nietzsche (Havi, 1986, 318), and Albert Camus (Nazeri and Sedighi, 2011, 130), and also Akhavan poetry, Nietzsche and Sartre using ideas, creating (Vaezzadeh and Qavam, 2010, 31), this type of struggle in the poems of these poets, expresses the opposition of doubt and certainty, but with the resurrection Havi Arab poetry, and the Akhavan poetry, otherworldly beliefs linked with cognition is. Life and death struggle, the struggle with the inherited traditions of other judicial, Havi and Akhavan relying on intellectual struggles, have to express it. But Havi always looking for a fight with tradition and innovation, and Akhavan sometimes struggle with the historic traditions, and sometimes paying them. Emotional struggle in both his poetry, from the face of despair and hope toward social change, he says, but in Havi poetry, linked with individual cases. The emotional struggle, in their poems drawing on purity and filth, or inferiority and self-esteem.

\section{References}

Akhavan Sales, Mahdi.(1981). from this Avesta, Tehran: Morvarid, Fifth Edition.

Akhavan Sales, Mahdi.(1982). the end of Shahnameh, Tehran: Morvarid, Fifth Edition.

Akhavan Sales, Mahdi.(2000). Winter, Tehran, Morvarid.

Algmh, Sobheh Ahmad.(2006). Overlap races in the novel dramatic literary model, the Arab Foundation for Studies and Publishing, Beirut, Dar jockey for Publishing and Distribution, Jordan, T 1.

Alqeysari, Faisal Saleh .(2006). Structure of the poem in the poetry of Ezzoddine advocacy, Majdalavi for Publishing and Distribution, Amman, Jordan, T1.

Baraheni, Reza.(1983).novelist, Tehran, No published, third edition. 
Farzi, Hamid Reza. (2012). archetypal criticism of "Tales of Sangestan" poetry of Mahdi Akhavan Sales Journal of mystical literature and mythology, Issue 28, pp.120-121

Hamadeh, Ebrahim.(1985). Lexicon dramatic terms, Cairo: Knowledge House

Havi, Elia.(1984). With Khalil Havi in the lines of his biography and his hair, Beirut,, Dar Alsegafah, T 1.

Havi, Elia.(1986). Khalil Havi; in the course of his life and his poetry, Beirut: Dar Alseqafah, T 1.

Havi, Khalil. (1972). the Court Khalil Havi, Beirut: Dar Alavdeh,T 1.

Havi, Khalil. (1993), the Court Khalil Havi, Beirut, Dar Alavdeh, D.T.

Hati Philip, (1987). Lebanon history, Dar Alseqafah: Beirut.

Hor, Abdol Hamid.(1995).Khalil Havi modernity and romance Poet, Darolkotob, Qualifications: Beirut. T1

Hoghooghi, Mohammad.(2014). the poetry of our time, 2 Mahdi Akhavan Sales, Tehran: Negah, print XVI.

Macci, Ebrahim.(1992). factors view, Tehran: Soroosh, Second Edition.

Mir Sadeghi, Jamal.(2008). a guide to writing, printing, Tehran, Sokhan.

Moin, Mohammad.(2007).certain Persian culture, Tehran: Behzad.

Nazeri, Hosein and Kalthoom Sedighi.(2011). the poetry of Khalil Havi studied existentialism, philosophical journal, Volume VII, No. 1/64, pp. 127-157.

Noori, Ali and Ahmed Kanjoorian.(2011). meaning, language and image in the Shahnameh poem, the Mahdi Akhavan Sales, study Persian Language and Literature, No. 22, Ss113-145.

Rezai, Arabali, (2003), literature descriptive words, Tehran's contemporary culture.

Shafie Kadkani, Mohammad Reza and Morteza Kakhi.(1991). Mehdi Akhavan Sales memorial garden leaf printing, Tehran

Shafie Kadkani, Mohammad Reza.(1989). mirror poet (check the Hindi style and Biddle lyrics), Tehran informed, Second Edition.

Shafie Kadkani, Mohammad Reza.(2001).the Arab poetry, printing, Tehran, speaking.

Soleiman, Mohammad.(2006).Cash movement about hope Denkul poetic experience, Oman, Dar Yazoori Scientific Publishing and Distribution, D.t.

Vaezzadeh, Abbas and Abolghasem Qavam.(2010). Effects of Akhavan poetry believe in God, Light and Shamloo, literary essays, Ferdowsi University, forty-third year, the first issue, pp. 25-49.

Zarghani, Seyed Mahdi.(2003). Akhavan in the mirror of his poem, Faculty of Literature and Human Sciences, Ferdowsi University, 36/3, 142 consecutive.

Zarghani, Seyed Mahdi.(2005). contemporary landscape Iran poetry, Tehran: Sales, Second Edition. 